\title{
News and Events
}

\section{Urban Rivers and Waterfronts: Workshop 12-14 December 1997, Calcutta, India Information: Centre for Built Environment, 2/5 Sarat Bose Road, Calcutta 700 020, India Tel: +9133476 1495. Fax: +91334660625 \\ Computers in Urban Planning \& Urban Manage- ment, 5th International Conference: Call for Abstracts \\ 16-19 December 1997, Bombay, India} Information: Dr P. K. Sidkar, Dr S. L. Dhingra, Centre for Built Environment, 2/5 Sarat Bose Road, Calcutta 700 020, India

Tel: +9133476 1495. Fax: +91334660625

Disasters: Cities and Building - Prevention, Resettlement and Development: Workshop 16-18 January 1998, Calcutta, India Information: Centre for Built Environment, 2/5 Sarat Bose Road, Calcutta 700 020, India Tel: +9133476 1495. Fax: +91334660625
Quality of Life in Cities - Issues and Perspectives: Conference

March 1998, Singapore

Information: Conference Secretariat, School of Building \& Estate Management, National University of Singapore, 10 Kent Ridge Crescent, Singapore 119260

Tel: +65 7723440

Making Cities Liveable: Conference

9-13 March 1998, La Playa Hotel, Carmel, California, USA

Information: Suzanne H. Crowhurst Lennard Program, Committee Chair, PO Box 7586, Carmel, CA 93921, USA

Tel: +408 626 908. Fax: +4086245126

\section{Uban Development Conference}

4-7 April 1998, Israel

Information: Tel: +9727647 2022. Fax: +9727627 8991 